\title{
Mediação e conceitos cotidianos: os aportes de Feuersteine Vygotsky para investigar as dificuldades de aprendizagem
}

Mediation and everyday concepts: the contributions of Feuerstein and Vygotsky to investigate learning difficulties

Mediación y conceptos cotidianos: las contribuciones de Feuerstein y Vygotsky para investigar las dificultades de aprendizaje

\author{
Adriane Cenci* \\ Fabiane Adela Tonetto Costas ${ }^{* *}$
}

\begin{abstract}
Resumo
A pesquisa propôs analisar, com base nos referenciais teóricos de Feuerstein e Vygotsky, as dificuldades de aprendizagem apresentadas por duas crianças (meninos, gêmeos de 10 anos, no $3^{\mathbf{o}}$ ano do ensino fundamental). As ideias centrais assumidas desses autores são referentes à mediação e formação de conceitos. A investigação prática desenvolveuse durante um semestre e organizou-se a partir de observação de aulas, intervenção pedagógica (atendimento educacional) com as crianças e entrevistas com os professores e a mãe. Tomando os princípios teóricos adotados como possibilidade de interpretação e compreensão do caso, evidenciou-se que a escassez de experiências de aprendizagem mediada acarretou incipiente desenvolvimento dos conceitos cotidianos nas duas crianças e que esses conceitos estão também na raiz das dificuldades escolares que elas enfrentam.
\end{abstract}

Palavras-chave: Experiência de aprendizagem mediada. Conceitos cotidianos. Dificuldades de aprendizagem. Feuerstein. Vygotsky.

\begin{abstract}
The proposed research is an analysis of learning difficulties presented by two children - 10 year-old twin boys, in the 3rd year of primary school - from the Vygotsky and Feuerstein's theoretical framework. The central ideas by these authors are refer to mediation and concept formation. Research practice was developed during one semester and was organized by observing lessons, pedagogical intervention (educational services)
\end{abstract}

Doutoranda em Educação pela Universidade Federal de Pelotas (UFPel), mestra em Educação pela Universidade Federal de Santa Maria (UFSM), licenciada em Educação Especial pela UFSM.

** Doutora em Educação pela Universidade Federal do Rio Grande do Sul (UFRGS), mestra em Educação pela UFSM, graduada em Pedagogia pela UFSM, professora associada I do Departamento de Fundamentos da Educação e professora do Programa de Pós-graduação em Educação da UFSM. 
with the children and interviews with their teachers and mother. Taking the theoretical principles adopted as a possibility for interpretation and understanding of the case, it became clear that the lack of mediated learning experiences led to incipient development of everyday concepts in both children and that these concepts were also at the root of learning difficulties they faced.

Keywords: Mediated learning experience. Everyday concepts. Learning difficulties. Feuerstein. Vygotsky.

\section{Resumen}

La investigación se propone analizar las dificultades de aprendizaje presentadas por dos niños (gemelos de 10 años, de $3^{o}$ de primaria) basados en el marco teórico de Vygotsky y Feuerstein. Las ideas centrales de estos autores se refieren a la mediación y la formación de conceptos. La investigación práctica se desarrolló a lo largo de un semestre y se organizó a partir de la observación en clase, intervención pedagógica (servicios educativos) con los niños y entrevistas con los profesores y su madre. Tomando los principios teóricos adoptados como posibilidad para la interpretación y comprensión del caso, se hizo evidente que la falta de experiencias de aprendizaje mediado supuso incipiente desarrollo de los conceptos cotidianos en los niños y que estos conceptos también están en la raíz de las dificultades escolares que enfrentan.

Palabras clave: La experiencia del aprendizaje mediado. Conceptos cotidianos. Dificultades de aprendizaje. Feuerstein. Vygotsky.

\section{Introdução}

A dificuldades de aprendizagem têm sido pesquisadas pelo viés $\triangle$ de várias perspectivas, conferindo ênfase distinta a fatores intervenientes conforme o olhar da teoria adotada. A discussão das dificuldades de aprendizagem que aqui adotamos provém de pesquisa do mestrado (Cenci, 2011) realizada no Programa de Pós-graduação em Educação da Universidade Federal de Santa Maria (UFSM), que buscou investigar como os processos mediados interferem na formação dos conceitos cotidianos, mais especificamente conceitos cotidianos matemáticos, e como estes últimos interferem na formação de conceitos científicos e na aprendizagem escolar, podendo desencadear dificuldades de aprendizagem. De modo específico, discutiu a relação entre conceitos 
cotidianos e conceitos científicos e a questão dos processos de mediação - sendo este último o tópico destacado neste texto.

Assim, fundamentamo-nos nas ideias de Feuerstein e Vygotsky, tendo como objeto de análise o tópico acima destacado da investigação supracitada. Esta foi realizada com duas crianças: meninos, WS e WL, ${ }^{1}$ gêmeos univitelinos de 10 anos que frequentavam o $3^{\circ}$ ano do ensino fundamental numa escola municipal em Santa Maria-RS, com alunos de classe socioeconômica predominantemente média e baixa. Os dois meninos vinham apresentando dificuldades na escola, tendo já histórico de reprovação. As reflexôes concentram-se, principalmente, nas ideias de aprendizagem mediada e formação de conceitos, e apresentam como resultados uma interpretação/explicação para a possível origem das dificuldades de aprendizagem observadas.

De acordo com Vygotsky (1993), os conceitos cotidianos são aqueles formados a partir de vivências, situações concretas e afetivas mediatas. Formamse a partir das propriedades perceptivas, isto é, da coisa em si. O autor também os denomina conceitos espontâneos, mas, na pesquisa, optamos por adotar conceitos cotidianos, pois, ainda que estes sejam adquiridos sem instrução explícita e sistemática, não se nega o papel de outras pessoas, geralmente adultos, em seu processo de formação. Já os conceitos científicos são aqueles que surgem de ações intencionais, mediante a instrução, principalmente nos processos formais de ensino.

Consideramos, assim, a influência da mediação pré-escolar no desenvolvimento dos conceitos cotidianos e partimos da compreensão de que não são somente os conceitos científicos necessitam de mediação específica; os conceitos cotidianos, embora relacionados à experiência direta, também precisam ser mediados para a criança deles se apropriar.

É também a mediação o eixo que melhor aproxima as teorias de Vygotsky e de Feuerstein. Nesse sentido, entendemos por processos mediativos a mediação/interferência de outras pessoas na relação do sujeito com o universo que o cerca. A experiência de aprendizagem mediada (EAM), de acordo com Feuerstein, Rand, Hofmann e Miller (1980), refere-se à mediação intencional de alguém selecionando e organizando os estímulos, proporcionando, assim, uma aprendizagem estruturada.

Por Experiências de Aprendizagem Mediada (EAM) nós nos referimos ao caminho no qual os estímulos emitidos pelo ambiente são transformados por um agente mediador,

\footnotetext{
1 Optou-se por usar siglas representando o nome das duas crianças, de modo a preservar-lhes a identidade.
} 
normalmente os pais, irmão ou outros. Esse agente mediador guiado por suas intençôes, cultura e investimento emocional seleciona e organiza o mundo de estímulos para a criança. $\mathrm{O}$ mediador seleciona os estímulos que são mais apropriados e então os molda, filtra, programa; ele determina a presença ou ausência de certos estímulos e ignora outros (Feuerstein, Rand, Hofmann \& Miller, 1980, p. 15-16, tradução nossa).2

O aprofundamento no referencial teórico aqui anunciado (principalmente a proposição de Experiência de Aprendizagem Mediada e a ideia de formação de conceitos cotidianos) será progressivamente entrelaçado com a exposição do caso pesquisado. Desse modo, após detalhar os encaminhamentos metodológicos, explicamos as perspectivas de Feuerstein e Vygotsky conforme vamos trazendo e interpretando a história de WS e WL, buscando compreender como as dificuldades de aprendizagem se constituíram e tentando estratégias para superá-las. ${ }^{3}$

\section{Percurso metodológico}

Viabilizando a investigação a respeito da influência da mediação para a formação de conceitos cotidianos como elementos nas dificuldades de aprendizagem (propostos como objetivos), a pesquisa configura-se como qualitativa, na perspectiva de Epistemologia Qualitativa descrita por González Rey:

A pesquisa qualitativa proposta por nós representa um processo permanente, dentro do qual se definem e se redefinem constantemente todas as decisões e opções metodológicas no decorrer do próprio processo de pesquisa, o qual enriquece, de forma constante, a representação teórica sobre o modelo teórico em desenvolvimento. (González Rey, 2005, p. 81).

A pesquisa que o autor defende é caracterizada pelo caráter construtivointerpretativo, dialógico, pela atenção dada ao estudo de casos singulares e aos processos subjetivos (González Rey, 2001). Em nossa investigação, procuramos preservar tais características.

\footnotetext{
2 "For Mediated Learning Experiences (MLE) we refer to the way in which the stimuli emitted by the environment are transformed by a mediator, usually parents, brother or others. This mediating agent guided by your intentions, cultural and emotional investment selects and organizes the world of stimuli for the child. The mediator selects stimuli that are most appropriate and then the mold, sift program, it determines the presence or absence of certain stimuli and ignores others".

3 Cabe pontuar que não foi objetivo fazer uma revisão teórica acerca dos estudos que também se centram nas dificuldades de aprendizagem. Deixamos clara a opção em interpretar o caso com base nas ideias de Feuerstein e Vygotsky.
} 
Estivemos em campo no período de um semestre (segundo semestre de 2009). ${ }^{4}$ Os dados e indicadores ${ }^{5}$ do estudo foram produzidos a partir de:

1) Observação semanal por parte de uma das pesquisadoras (uma ou duas vezes por semana) dos alunos/sujeitos durante suas aulas. As anotações foram registradas em diário de campo, posteriormente transcrito e ampliado com base em um maior detalhamento do observado.

2) Atendimento pedagógico por parte de uma das pesquisadoras (uma vez por semana) em sala de recursos, no turno oposto ao que frequentavam as aulas normais, durante, aproximadamente, 1 hora e 30 minutos. Este se configurou como intervenção pedagógica visando a observar e desenvolver o processo de formação de conceitos cotidianos e científicos nas duas crianças. Por vezes, o trabalho de intervenção foi realizado fora da escola.

Como o foco da pesquisa esteve na formação dos conceitos cotidianos, acreditamos que, nas atividades fora da escola, estivesse uma fonte importante de indícios para responder ao questionamento: "como se desenvolvem os conceitos cotidianos e com quais conceitos cotidianos matemáticos os meninos lidam?". Para tanto, foram propostas atividades corriqueiras, durante as quais se abordaram questôes cotidianas relacionadas à matemática, envolvendo noções de espaço, distância, tempo, dinheiro, peso, etc. Situações como idas ao supermercado, divisão de chocolates, acompanhar e anotar o horário de algumas atividades diárias, como a hora de acordar, a hora em que a aula começa, a hora do recreio, a hora em que almoça, a hora em que vai dormir, atentar e anotar também a duração de alguns fatos cotidianos, como quanto tempo há entre o início e o fim do desenho animado preferido, do filme que passa na televisão, da novela (cada uma dessas atividades tendo planejamentos específicos).

As situações planejadas tinham o intuito de colocar os sujeitos diante de problemas que ainda não conseguem resolver, mas que estão próximos, na zona de desenvolvimento proximal - ZDP. Ao solucioná-los, com a ação mediada necessária, as crianças avançam no desenvolvimento.

\footnotetext{
É importante mencionar que, desde o segundo semestre de 2007, já vínhamos trabalhando com WS e WL. O estágio curricular em dificuldades de aprendizagem do curso de Educação Especial (Universidade Federal de Santa Maria) de uma das pesquisadoras teve, naquele ano, os dois meninos como sujeitos. Posteriormente continuamos na mesma escola com outros trabalhos, podendo acompanhar o desenvolvimento escolar de WS e WL. Contudo o registro sistemático para a pesquisa aqui apresentada inicia-se em 2009, como indicado.

Falamos em produção de dados, corroborando com González Rey (2005) quando afirma que os dados não se coletam, mas se produzem, eles são inseparáveis do processo de construção teórica, e só dentro do processo ganham sentido; a interpretação do pesquisador é que produz, dá significado ao dado. De acordo com tal proposta metodológica, a ideia de dado pode ser complementada pela de indicadores. Os indicadores têm relevância dentro do marco teórico que vem se estabelecendo e estes não têm caráter absoluto, representam apenas um primeiro momento nas interpretações que o pesquisador vem tecendo.
} 
Os atendimentos pedagógicos, tanto em sala de recursos quanto nas situações cotidianas, foram gravados e transcritos na íntegra. Um diário de campo também foi usado, de modo a ajudar na organização das transcrições e para destacar os eventos que percebíamos como mais interessantes.

3) Entrevista semiestruturada com as professoras da série atual e anterior. Instrumento que teve o intuito de traçar o desenvolvimento escolar das crianças, perceber as dificuldades e os avanços nesse percurso.

4) Entrevista semiestruturada com a mãe das crianças, investigando fatos importantes (questões relativas ao nascimento, relaçôes pessoais das crianças, atividades de interesse, condições socioeconômicas e acesso a bens culturais, etc.), para compreender o desenvolvimento biológico e psicológico desde os primeiros anos de vida.

Quanto às entrevistas semiestruturadas, estas foram orientadas com base na perspectiva de Triviños (1987). Além de importante leitura para orientar o uso do instrumento, o autor também esclarece que as perguntas da entrevista não nasceram a priori, elas estão relacionadas à teoria que guia o pesquisador e às informações que ele já conhece acerca da situação que está sendo estudada (Triviños, 1987).

Os indicadores produzidos nesses instrumentos foram organizados em três grandes eixos ou categorias: 1) a relação entre conceitos cotidianos e científicos, 2) a influência da mediação na formação de conceitos cotidianos e 3) a subjetividade no processo de formação conceitual e nas dificuldades de aprendizagem. A seguir explicitamos, predominantemente, o segundo eixo. ${ }^{6}$

\section{Mediação e conceitos cotidianos: os aportes de Feuerstein e Vygotsky para investigar as dificuldades de aprendizagem}

Vygotsky (1993), ao propor que os conceitos cotidianos são fruto da mediação em idade pré-escolar, assim como os conceitos científicos o são resultantes da instrução formal escolar, enfatiza a importância dos processos mediados na aprendizagem; tanto aprendizagem formal/escolar como cotidiana. Entretanto, como Vygotsky destaca a mediação/instrução na formação dos conceitos científicos e diz que os conceitos cotidianos se relacionam à experiência direta do sujeito, há frequentemente uma leitura que ignora o papel da mediação nos conceitos cotidianos.

Entendemos que, quando Vygotsky fala em experiência direta, ele não exclui

6 O recorte de apenas um eixo é necessário para que, num texto relativamente breve, se consiga aprofundar adequadamente as reflexôes. 
o papel dos outros que organizam e explicam à criança esse meio com a qual ela se relaciona. Nessa direção, as ideias de Feuerstein vêm oferecer subsídios para reafirmar e ampliar a proposição vygotskyana acerca da mediação nos conceitos cotidianos. Feuerstein tem um entendimento amplo de mediação que cabe tanto para pensarmos os conceitos cotidianos quanto os conceitos científicos.

Feuerstein, Klein e Tannenbaum (1994) compreendem a mediação humana como a possibilitadora das aprendizagens. $\mathrm{O}$ ato de mediação é:

[...] uma interação qualitativa entre o organismo e seu meio ambiente. Esta qualidadeéassegurada pela interposição intencional de um ser humano que medeia os estímulos capazes de afetar o organismo. Este modo de interação é paralelo e qualitativamente diferente das modalidades de interação generalizadas e difusas entre o mundo e o organismo, conhecido como contato direto com o estímulo (Feuerstein, Klein \& Tannenbaum, 1994, p. 7).7

A mediação tem caráter de verdadeira implicação dos sujeitos na relação interpessoal. Não é qualquer ação ocorrida entre duas pessoas que ele considera mediação (é ação significativa).

A delimitação que o autor propõe é por entender que nem toda mediação possibilita aprendizagem. Ele estabelece, então, critérios sem os quais não há força mediadora. Da série de componentes essenciais, Feuerstein, Klein e Tannenbaum (1994), e Giugno (2002) enfatizam três: a mediação da intencionalidade e reciprocidade, da transcendência e do significado. Esse "tripé" é necessário para qualificar uma experiência de aprendizagem mediada.

Podemos dizer que essas condições de mediação estiveram presentes nas intervençôes pedagógicas elaboradas para os meninos. As atividades tinham objetivos claros e eram organizadas de modo a contemplar as características das crianças no intuito de implicá-las no exercício (mediação de intencionalidade e reciprocidade).

Os planejamentos visavam a que as aprendizagens de cada intervenção pudessem ser aplicadas em outros contextos (em sala de aula e em atividades fora da escola, como ir ao mercado, saber as horas, compreender os pontos de um jogo, aprender novas brincadeiras) e fossem importantes na realidade diária dos meninos (mediação da transcendência). As intervenções eram

Tradução nossa. Texto original: "[...] qualitative interaction between the organism and its environment. This quality is ensured by the interposition of a human being intentionally mediating stimuli can affect the organism. This mode of interaction is parallel and qualitatively different modes of interaction generalized and diffuse between the world and the organism, known as direct contact with the stimulus". 
pensadas de acordo com o que se percebia do interesse das crianças e das questōes que iam surgindo em nossa interação, de modo a não serem apenas exercícios mecânicos, mas atividades significativas (mediação do significado).

A mediação está para além da interação social. A mediação, segundo a concepção de Feuerstein, é a situação na qual o mediador interfere na ação com o propósito de direcionar a aprendizagem. Nessa perspectiva, a mediação promoverá a aprendizagem; essa é característica essencial para assim poder nomeá-la. Porém nem sempre a interação supõe situações de aprendizagem.

Baquero (1998), ao fazer menção à interação na perspectiva vygotskyana, aproxima-a das ideias de Feuerstein:

O auxílio ou assistência dada pelo sujeito com maior domínio deve reunir uma série de características, as quais não foram claramente desenvolvidas por Vygotsky. Obviamente nem toda situação de interação entre pessoas de competência desigual gera desenvolvimento (Baquero, 1998, p. 98).

Vygotsky não especificou a questão da assistência (pode-se ler aqui mediação), disse apenas que a "boa aprendizagem" é a que promove desenvolvimento. Contudo não definiu o que seria "boa", apenas fez referência à zona de desenvolvimento proximal, sem elaborar as características da boa aprendizagem. As categorias de mediação propostas por Feuerstein podem ser entendidas como complementares a elaboração de Vygotsky. Ainda que os autores não coincidam em todos os aspectos, as linhas gerais de pensamento são aproximadas.

Quando a interação vem no propósito de aprendizagem, é chamada de mediação, ou melhor, numa acepção mais precisa de Feuerstein, a denominamos de Experiência de Aprendizagem Mediada (EAM).

Então Feuerstein estabelece dois modos de interação com o mundo: a exposição direta aos estímulos e a experiência de aprendizagem mediada, na qual o mediador seleciona os estímulos, proporcionando aprendizagem organizada e estruturada. Para o autor (1980, citado também por Sarmento \& Beyer, 2000), o último modo é responsável pelo desenvolvimento cognitivo e pelas funções humanas mais elevadas, sendo a exposição direta insuficiente para a expansão dos sistemas perceptuais a um nível mais abstrato.

Desde muito cedo, os adultos vão delimitando as coisas que a criança conhece e compreende, ao selecionar estímulos fazendo com que a criança atente a uns e não a outros se está organizando a aprendizagem. De acordo com Feuerstein: 
[...] Em interações típicas, como as de mãe-filho, abundam as situações de aprendizagem mediada. [...] Ela atribui significados específicos a eventos, relaçóes temporais, espaciais, causais e outras não inerentes tanto ao objeto como às ações da criança. Estas são mediadas pela mãe ou por outras figuras envolvidas com os cuidados da criança. Além de transmitir todos os tipos de informaçôes específicas, que simplesmente não estão disponíveis via exposição [...], o aprendizado mediado provê o tipo de experiência necessária para a formação da estrutura cognitiva que possibilita a apropriação da cultura (Feuerstein, 1981, citado por Zanatta da Ros, 2002, p. 33-34).

Remetendo-nos ao caso da pesquisa, refletimos como devem ter sido os primeiros anos de vida de WS e WL. Segundo o observado e os relatos da mãe e dos professores, imaginamos as situaçôes restritas de aprendizagem às quais os meninos tiveram acesso.

$\mathrm{Na}$ última conversa com a mãe, ela reforçou o que os meninos já contavam acerca de quase não saírem de casa:

PESQUISADORA: Além da escola, eles têm alguma outra atividade?

MÂE: Eles vão na igreja, né. Depois só em casa. Nem pastoral já não têm idade mais. Só de vez em quando que sai.

PESQUISADORA: Eles têm bastante amigos na rua?

MÃE: Sim, mas eu não deixo.

PESQUISADORA: Eles brincam mais entre eles?

$M A \tilde{E}: \hat{E}$, só eles. Não deixo muito por causa que aqui brigam, se ajuntam.

(Entrevista com a mãe, 15 de dezembro de 2009).

A rotina deles é ir à escola e passar o dia em casa, sozinhos. A mãe é empregada doméstica e sai para o trabalho quando os meninos vão à escola, quando eles retornam, encontram em casa os dois irmãos mais velhos que, em seguida, vão para a escola. Assim, os dois passam a tarde sozinhos, em casa, até a hora em que a mãe chega, por volta das 16 horas.

Nesse contexto, as situações de aprendizagem mediada são mais restritas. A interação limitada a brincadeiras somente entre irmãos devia ser ainda mais predominante no período anterior ao ingresso na escola. A conversa com a professora do $2^{\circ}$ ano também pontua essa percepção: 
PROFESSORA 1: Eles chegaram quase que uma página em branco. Algum rabisco eles trouxeram. Agora se tu me perguntar o que tu conseguiu fazer nesses dois anos, eu consegui mostrar que eles tinham que se desafiar, que eles eram capazes, mas que eu não poderia mexer na cabecinha deles se eles não quisessem.

(Entrevista com a professora da série anterior, 10 de dezembro de 2009.)

A professora trabalhou com os meninos nos dois anos em que eles cursaram o $2^{\circ}$ ano do ensino fundamental. Ela os acompanhou em seus primeiros anos escolares, e o relato, apesar do tom forte, é uma importante informação sobre o início da escolarização.

Juntando os indicadores provindos das conversas e do trabalho junto às crianças, vai-se configurando o desenho de uma realidade condizente com a hipótese de que as dificuldades de aprendizagem podem, sim, ter relação com os conceitos cotidianos, mas, olhando somente para a escola, não podemos enxergar como se construiu essa interferência. O olhar para outras situações vem possibilitando tecer interpretações com base na teoria estudada, percebendo que os conceitos científicos necessitam de um nível de desenvolvimento dos conceitos cotidianos, mas que esses conceitos cotidianos são dependentes, também, de situações de aprendizagem mediada.

A investigação sopesa períodos bem anteriores à manifestação da dificuldade de aprendizagem na escola e procura reconstruir informações com base em situações consideradas cotidianas em nossa sociedade para uma criança de 10 anos, procurando indícios que apontem o modo de pensamento dos gêmeos.

Assim, atividades como compras no mercado (valoração das mercadorias) e estabelecer as horas que demarcam atividades diárias (acordar, almoçar, ir à escola) são ilustrativas da necessidade de formação conceitual cotidiana.

Nas idas ao mercado e na brincadeira de mercadinho, averiguouse que os meninos têm também dificuldade em situações matemáticas extraescolares. A compreensão de reais e centavos é instável, decifram os números com dificuldade, e a atribuição do valor é ainda mais penosa.

PESQUISADORA: Isso aqui dá pra comprar? Tá onze reais. (Estão olhando pacotes de bala) 
WL: Dá.

PESQUISADORA: Com sete reais dá pra comprar?!

WL: Não.

PESQUISADORA: Não dá a bala, nem essa daí.

[...]

WL: Sora [professora]. (Olhando as bolachas)

PESQUISADORA: Esse é quanto?

WL: Oito e zero.

PESQUISADORA: Oitenta.

WS: Dá pra levar.

[discutem entre si, mas não dá pra entender]

PESQUISADORA: Se não der, vocês vão devolver.

WL: Se ela falar que vai sobrar, a gente compra mais esse ou outra coisa.

WS: Tá.

(20 de outubro de 2009, no mercado, durante atendimento especializado.)

PESQUISADORA: Quantos reais?

WL: Trinta centavos.

PESQUISADORA: Quantos reais?

WS: Cinquenta centavos.

PESQUISADORA: O que tá antes da vírgula é real. Quanto é que tem?

WL: Três.

PESQUISADORA: Três reais e quantos centavos?

WL: cinco.

(20 de outubro de 2009, durante atendimento especializado.)

A compreensão do conceito de real e centavos envolve um nível de abstração que os meninos não alcançaram, envolve ainda experiências prévias com esse conteúdo durante as quais, pela exploração, vão desvendando as relações existentes.

No bairro onde moram, há apenas um mercado maior (ao qual fomos), que fica próximo da escola e da casa das crianças. No caixa, conversando com 
a moça que aí trabalha, procuramos saber como as crianças costumam se comportar nesse espaço.

PESQUISADORA: Quanto deu, moça?

CAIXA: Aqui deu seis e oitenta.

PESQUISADORA: Será que a gente tem dinheiro que chega? Pede pra ela contar pra vê se tem.

CAIXA: Separadinho aqui, ó! (Faz seis montinhos de um real.)

PESQUISADORA: Quando eles vêm aqui, eles sabem contar o dinheiro certinho?

CAIXA: Eles não vêm muito. Quem vem mais é a mãe deles.

(20 de outubro de 2009, no mercado, durante atendimento especializado.)

Lidar com dinheiro, fazer compras, pensar em quanto se gastou, calcular o troco, são várias as possibilidades de exploração de situações de aprendizagem matemática no supermercado. Ao que tudo indica, as crianças tiveram escassas experiências desse tipo.

Outra situação investigada é referente à compreensão das horas. Ler as horas no relógio analógico é uma aprendizagem que leva algum tempo, no entanto as crianças, em geral, conhecem e sabem as horas em que realizam determinada atividade, ainda que não conheçam a configuração dos ponteiros atinentes a ela.

Elaboramos atividades que levassem os meninos a acompanhar as horas de algumas atividades também olhando para o relógio. Numa das intervenções, os meninos ganharam relógios analógicos e deveriam, durante a semana, anotar num diário a hora em que realizaram as atividades aí predeterminadas. Esperávamos, com isso, obter informações de como as crianças entendem as horas e ainda fornecer subsídios, colocá-las em situações que possibilitassem o despertar das funções relacionadas.

As respostas vieram, mais uma vez, reforçar a ideia de uma privação de experiência com o conteúdo específico:

PESQUISADORA: Que horas tu acorda? O ponteiro pequeno no dez?

WS: Não (muda).

PESQUISADORA: Que horas tu acorda?

WS: Oito e quatro. 
PESQUISADORA: Ponteiro pequeno no oito quer dizer oito horas, o grande no quadro quer dizer vinte minutos. Tu acorda oito e vinte?! Tu chega a tempo da aula?

WS: $E^{\text {. }}$

PESQUISADORA: Tu acorda oito e vinte, e se a aula começa às oito, como é que tu chega a tempo pra aula?

WL: Mas a gente chega, não bateu ainda.

WS: $E_{\text {. }}$

(24 de novembro de 2009, durante atendimento especializado.)

Durante essa atividade exposta, ocorrida após a semana em que deveriam acompanhar as horas, trabalhávamos com relógios de EVA, cujos ponteiros os meninos manipulavam. O modo de eles ajustarem os ponteiros parecia aleatório; o alto nível de abstração que exigiu a atividade tornava distante da ZDP as intervenções, mediações, propostas, o que levou os meninos a agir "aleatoriamente".

Como os alunos trouxeram os diários preenchidos, continuamos questionando para saber como chegaram às respostas. Nessa conversa, ficou claro que os meninos também não lidam com as horas de modo a organizar o dia.

Assim, perguntas referentes a "que hora você faz tal atividade?" eram respondidas de acordo com a forma como faziam a atividade:

PESQUISADORA: A aula começa que horas?

WL: Começa, nós copia a data.

PESQUISADORA: Não. Que horas começa a aula?

(WL não responde.)

(24 de novembro de 2009, durante atendimento especializado.)

PESQUISADORA: Que horas que começou a aula?

WS: A gente conversa, conversa, conversa, depois faz a oração, depois começa.

(24 de novembro de 2009, durante atendimento especializado.)

As repostas dos meninos mostram o pensamento arraigado na experiência concreta, nas vivências, relato de fatos apenas. Questionamos WS e WL se não estavam acompanhando as horas no relógio durante a semana; a experiência teria sido enriquecida e poderia proporcionar subsídios às respostas que envolvessem as horas. Segue a réplica das crianças: 
PESQUISADORA: Tu não anda com o relógio no braço? Faz o que com o relógio?

WS: Ah, olho as horas. O que mais eu vou fazer com o relógio?

WL: A mãe não deixa a gente pega o relógio pra brincar. A gente pega

"Vai lá, tira o relógio!".

(WS ri.)

(24 de novembro de 2009, durante atendimento especializado.)

O cotidiano dos meninos é apartado desses artefatos culturais e, quando foi proposto inseri-los, não logramos êxito. Na sequência do excerto acima, os meninos desconversam; em outra oportunidade, dizem que a mãe só os deixa usarem o relógio "pra sair". Ao não conseguirem responder a quaisquer questionamentos acerca das horas, acabam admitindo que a irmã mais velha foi quem preencheu os diários.

Enfim, mais uma vez, os indicadores apontam para a escassez de experiências mediadas. Ao que parece, os adultos que convivem com os meninos não utilizam referências às horas na interação com eles.

Pensando nessa interação adulto-criança de uma maneira geral, percebemos abundantes situações em que se fala em horas, por exemplo: "São 7 horas, é hora de acordar pra ir à escola", "São 11 e meia, vá lavar as mãos para o almoço", "Já são 10 horas, desligue a tevê e vá dormir", "O filme começa às 3 horas". As crianças costumam questionar, assim as explicações dadas e as experiências vão servindo de referências para a elaboração do conceito de horas e compreensão da organização desse sistema que mede o tempo.

Os pressupostos de Feuerstein indicam que o desenvolvimento e aprendizagem dependem da qualidade das interaçôes sociais, ou seja, dependem das EAM (interações ideais). No caso investigado, as informaçôes e indicadores sugerem que insuficiente EAM pode estar relacionada com as dificuldades de aprendizagem.

Partindo desse princípio, temos em Feuerstein, a explicação do não aprender da criança como consequência de uma interrupção na dinâmica destas trocas sociais. Para ele, o desempenho escolar não satisfatório do aluno pode ser explicado bem mais como decorrência de uma falta de mediação adequada do que como algum comprometimento de origem biológica. Portanto, numa visão feuersteiniana, as falhas de mediação humana no processo de aprendizagem da criança podem resultar em defasagens cognitivas que, por sua vez, implicarão no surgimento de funções cognitivas deficientes (Giugno, 2002, p. 64). 
A ausência de EAM produziria funções cognitivas deficientes. O termo deficiente não tem caráter pejorativo nem implica rigidez ou imutabilidade do quadro. O termo indica que as funções que servem de base ao pensamento interiorizado, representativo e operativo estão deficientes (Beltrán, Gutiérrez \& Vilaró, 1991).

As funções cognitivas deficientes, as dificuldades cognitivas, segundo Feuerstein, seriam influenciadas pela questão da mediação. Então, Feuerstein (1980, citado por Sarmento \& Beyer, 2000) propõe diferenciar os fatores proximais e distais. Os fatores proximais são determinantes, sendo referentes à qualidade da interação, às experiências de aprendizagem mediada. Os fatores distais compreendem as condições orgânicas, hereditariedade, situação emocional, nível socioeconômico, etc. Estes últimos têm influência, mas podem ser superados em presença de EAM.

No caso dos meninos da pesquisa, quanto aos fatores distais, pontuamos que, referente às condições orgânicas e hereditariedade, não havia nada atestado; alguns professores mencionam desconfiar de algum problema neurológico que justifique as dificuldades, mas não há comprovação médica ou mesmo fenotípica para tanto. Grande parte dos colegas dos meninos tem mesmo nível socioeconômico que os gêmeos e não apresentam dificuldades acentuadas.

Feuerstein fala em privação cultural com base na ideia de ausência da mediação de experiências em seu grupo cultural. Para Feuerstein (1997, p. 17), a privação cultural é demarcada como "um estado de reduzida modificabilidade cognitiva de um indivíduo, em resposta à exposição direta às fontes da informação".

Para não gerar confusões, é preciso ficar claro:

[...] Nossa utilização do termo "privação cultural" não responsabiliza a cultura do grupo ao qual o indivíduo pertence. Não é a cultura que é fator de negação. O que é prejudicial é o fato de indivíduos - ou grupos - serem privados de sua própria cultura. Nesse contexto "cultura" não é um inventário estático de condutas, mas o processo pelo qual os conhecimentos, os valores e as crenças são transmitidos de uma geração para outra. Neste sentido, a privação cultural é o resultado de o grupo não transmitir ou mediar sua cultura às novas gerações (Feuerstein, 1980, citado por Zanatta da Ros, 2002, p. 44).

A definição de Feuerstein está em consonância com as pesquisas que ele desenvolveu junto a crianças imigrantes, órfãos, refugiadas de guerra que, 
sozinhas, em um novo lugar, estavam privadas da mediação de um grupo cultural. 8

E se o eixo central é a mediação, então há possibilidades de reverter o quadro de privação cultural. Na verdade, os programas de avaliação (o LPAD - Abordagem da Avaliação do Potencial de Aprendizagem) e enriquecimento (o PEI - Programa de Enriquecimento Instrumental) elaborados por Feuerstein vêm com esse intuito. A base de ambos reside na premissa da capacidade de modificação cognitiva do ser humano (Beyer, 1996). A categoria modificabilidade é central na obra do autor, e sua pesquisa vem apostando na capacidade de transformação cognitiva do ser humano a partir da aprendizagem.

Para que seja superado o quadro de privação cultural, Feuerstein entende que são necessárias situações mediadas específicas, situações de aprendizagem.

A condição gerada pela privação cultural não é irreversível. $\mathrm{O}$ processo de mudança, no qual o aprender promove o desenvolvimento dá-se pela aproximação ou interação mediada ativa, isto é, a que concebe o ser humano como capaz de se transformar. Interação mediada é a que pode restituir a possibilidade de se relacionar com o mundo de forma diferente daquela marcada pela condição de "deficiente" ou de privado cultural (Zanatta da Ros, 2002, p. 45).

A mediação é responsável pela modificabilidade do ser humano. Feuerstein estabelece que as EAM reestruturam os processos prejudicados pela sua ausência em tempos anteriores e podem ainda transcender os limites biológicos impostos por síndromes ou outros quadros de alteração patológica.

A EAM é considerada fator proximal, primordial no desenvolvimento e aprendizagem, enquanto as questôes orgânicas fazem parte dos fatores distais, isto é, secundários (que podem ser suplantados em presença de EAM).

AEAM promove a modificabilidade, pois permite transformações cognitivas de modo a tornar o sujeito progressivamente autônomo nos aspectos que lhe foram possibilitados aprender. Sarmento e Beyer explicam o processo:

Um ser humano interpõe-se entre o organismo e os estímulos oferecidos pelo meio. Este mediador possui a intencionalidade de fazer com que tais estímulos sejam percebidos de forma

\footnotetext{
Cabe ressaltar (para não confundir com outras linhas teóricas) que o conceito de privação cultural que Feuerstein propõe não tem relação direta com questões de classe social, socioeconômica. Para o pesquisador, privação cultural é entendida com base na ausência de mediação estruturada; e isso pode acontecer em qualquer nível econômico; embora, com frequência, se apresente nas classes de menor poder aquisitivo.
} 
diferenciada do que se estivesse exposto diretamente a eles. No entanto, esta interposição entre o indivíduo e o estímulo tende a se reduzir com o decorrer do tempo, pois a EAM afeta sua estrutura interna, possibilitando-lhe que aprenda a aprender e desenvolva sua autonomia para estabelecer a seleção e organização de tais estímulos e, em decorrência, beneficiar-se deles para o seu desenvolvimento cognitivo. (Sarmento e Beyer, 2000, p. 5).

A possibilidade de aprender a aprender denuncia o caráter aberto da inteligência humana e permite nos adaptarmos às diferentes situações que se apresentam no dia a dia. A aprendizagem organizada dá condiçóes de o sujeito modificar-se cognitivamente, promove desenvolvimento.

Retomando o caso da pesquisa, imaginando que os gêmeos tiveram escassas situações de aprendizagem mediada, de intervenção de adultos estruturando e direcionando as aprendizagens nos primeiros anos de vida, inferimos que isso implicou em dificuldades no período escolar. No entanto é preciso também pontuar que o ensino escolar se organiza nos moldes de uma aprendizagem estruturada:

O professor, ao tratar o tema com o aluno, dava explicações, proporcionava conhecimentos, fazia perguntas, corrigia, obrigava o próprio aluno a dar explicações. Todo esse trabalho com relação aos conceitos, todo o processo de sua formação a criança realizou em colaboração com os adultos, durante o processo de instrução (Vygotsky, 1993, p. 248).9

Os conceitos científicos ensinados na escola, com sua formalização e estruturação, deveriam interferir na estruturação cognitiva na condição de experiências de aprendizagem mediada. Percebemos, assim, que a instrução do professor pode equivaler à aprendizagem mediada proposta por Feuerstein.

Seguindo na hipótese de que as dificuldades de aprendizagem dos meninos WS e WL se devessem à ausência de EAM, principalmente nos anos anteriores à escola, as intervenções em sala de aula, ainda que deparassem as barreiras impostas pela privação, deveriam promover algum avanço a partir das aprendizagens das quais os meninos conseguissem se apropriar. E isso, de fato, veio acontecendo.

Acompanhando os meninos durante aproximadamente dois anos e meio, pudemos perceber como eles interagiram mais com os colegas, passaram a

\footnotetext{
Tradução nossa. Texto original: "El maestro, al tratar el tema con el alumno, daba explicaciones, proporcionaba conocimientos, hacía preguntas, corregía, obligaba al propio alumno a dar explicaciones. Toda esta labor con relación a los conceptos, todo el proceso de su formación la realizó el niño en colaboración con los adultos, durante el proceso de la instrucción".
} 
estabelecer diálogos e narrações compreensíveis, apropriaram-se de alguns conceitos científicos a partir do conteúdo escolar, ainda que estivessem aquém do esperado para crianças de 10 anos. WL já escreve sozinho, WS lida com hipóteses mais elaboradas de escrita que anteriormente, ambos conhecem os números e as operações matemáticas, apesar de não resolverem todas elas.

Acima pontuamos a fala da professora do $2^{\circ}$ ano, dizendo que os meninos chegaram "uma página em branco" na escola e que as dificuldades deles resistiam à instrução. A conversa com a professora do $3^{\circ}$ ano já traz indicadores de que a instrução escolar vem, sim, interferindo no desenvolvimento das crianças

PESQUISADORA: Bem, acho que era isso. Tem mais alguma coisa que você ache relevante?

PROFESSORA 2: Não. Acho que foi falado o mais importante. Eu percebo bastante progresso, principalmente no WL. Teve bastante coisa positiva nesse ano. Tô vendo que ele vem superando a dificuldade. Ele quer aprender, ele tá comprometido. Enquanto o outro tá mais acomodado, mais parado, esperando.

(Entrevista com a professora da série atual, 15 de dezembro de 2009.)

Se, nos primeiros tempos na escola, o que mais se destacava era a dificuldade de aprendizagem acentuada e o retraimento, depois de quatro anos frequentando esse espaço, é possível perceber indícios de que a interação com outras crianças e a instrução organizada vêm interferindo positivamente no desenvolvimento dos meninos.

O ensino escolar se fundamenta na premissa de que experiências de aprendizagem mediada (EAM) proporcionarão às crianças se apropriarem das aprendizagens/conteúdos mediados. Os conceitos científicos são estudados em situações de aprendizagem mediada. Interpretamos, então, que as conquistas recentes dos meninos se justificam, em parte, por essa exposição à EAM.

Como observado, no início da escolarização, a escassez de EAM ou a carência de instrução pré-escolar impunham maiores empecilhos à aprendizagem, mas a inserção na escola e a mediação/instrução podem ser vistas como fatores que vêm minimizando os danos da falta de estímulos em períodos anteriores.

\section{Considerações finais}

Estudar as dificuldades de aprendizagem a partir da formação de conceitos cotidianos e dos processos mediativos envolvidos mostrou-se profícuo, uma vez que a aprendizagem escolar (ou seja, os conceitos científicos) se efetiva 
quando se relaciona o novo conhecimento à estrutura cognitiva presente e aos conceitos já consolidados. Assim, em vez de investigar a dificuldade de aprendizagem localizando-a apenas em sala de aula, buscamos ampliar a análise, atentando aos processos que ocorrem para além da escola e processos que se iniciam muito da escolarização. $\mathrm{Na}$ investigação das dificuldades de aprendizagem, no caso dos dois meninos, olhamos para além da aprendizagem escolar: para além e antes de se formarem os conceitos científicos, estão os conceitos cotidianos.

Cabe enfatizar que as duas formações conceituais (conceitos cotidianos e conceitos científicos) fazem parte do mesmo processo, ainda que se constituam sob diferentes condições: os conceitos cotidianos têm a sua formação ligada à experiência direta do sujeito, e os conceitos científicos são constituídos com base em processos de instrução sistematizada.

A estreita ligação entre as duas formas conceituais parte do princípio de que conceitos científicos se consolidam se forem estabelecidas relações com conceitos cotidianos anteriormente internalizados. Nesse processo, também os conceitos cotidianos seriam reorganizados pela estruturação dos conceitos científicos. Ocorre que, em alguns casos, como no dos meninos WS e WL, os conceitos cotidianos são incipientes e não constituem base suficiente para que os conceitos científicos se efetivem. Dessa forma, a dificuldade na consolidação dos conceitos científicos, devido à rudimentar formação conceitual cotidiana, está gerando as dificuldades de aprendizagem.

Constatada a relação de interdependência entre conceitos cotidianos e científicos, verificando que a formação conceitual é um processo único e integral, e que as fissuras nos conceitos cotidianos podem se tornar empecilhos na aprendizagem escolar, investigamos o porquê dessas lacunas nos conceitos cotidianos. A mediação, então, ganhou destaque.

$\mathrm{Na}$ análise do caso, ficou evidenciado que a escassez de experiências de aprendizagem mediada acarretou o incipiente desenvolvimento dos conceitos cotidianos nas duas crianças e que estes estão também na raiz das dificuldades escolares que elas enfrentam.

\section{Referências}

Baquero, R. (1998). Vygotsky e a aprendizagem escolar. Porto Alegre: Artes Médicas. 
Beltrán, J. M., Gutiérrez, J. J., Vilaró, R. (1991). Metodología de la mediación el en P.E.I. Madrid: Bruño.

Beyer, H. O. (1996). O fazer psicopedagógico: a abordagem de Reuven Feuerstein a partir de Vygotsky e Piaget. Porto Alegre: Mediação.

Cenci, A. (2011). Processos mediativos e formação de conceitos cotidianos: implicaçôes nas dificuldades de aprendizagem. Dissertação de Mestrado, Universidade Federal de Santa Maria, Santa Maria.

Feuerstein, R., Rand, Y., Hoffman, M. B., Miller, R. (1980). Instrumental enrichment: an intervention program for cognitive. Scott: Foresman and Company. Illinois: Glenview.

Feuerstein, R., Klein, P. S., Tannenbaum, A. J. (1994). Mediated learning experience (MLE): theoretical, psychosocial and learning implications. London: Freund, 1994.

Feuerstein, R. (1997). Teoria de la modificabilidad cognitiva estructural. In R. Feuerstein. Es modificable la inteligencia? (pp. 11-23). Madrid: Bruño.

Feuerstein, R. (1991). La modificabilidad cognitiva y el PEI. In Martinez Beltrán, J. M., Brunet Gutiérrez, J. J., Farrés Vilaró, R. Metodología de la mediación el en P.E.I. (pp. 7-14). Madrid: Bruño.

Giugno, J. L. D. P. (2002). Desvelando a mediação do professor em sala de aula: uma análise sobre as perspectivas de Vygotsky e Feuerstein. Dissertação de Mestrado, Universidade Federal do Rio Grande do Sul, Porto Alegre.

González Rey, F. L. (2001). A pesquisa e o tema da subjetividade em educação. Anais 24a Reunião Anual Associação Nacional de Pós-Graduação e Pesquisa em Educação (pp. 1-6). Caxambu: Anped.

González Rey, F. L. (2005). Pesquisa qualitativa e subjetividade: os processos de construção da informação. São Paulo: Pioneira Thomson Learning.

Sarmento, D. F., Beyer, H. O. (2000). A mediação no processo de ensino e aprendizagem.In Educação em Revista: ensaios organizados pelo Centro Marista de Estudos e Pesquisas - Cemep. (pp. 1-11). São Paulo: ABEC.

Triviños, A. N. S. (1987). Introdução à pesquisa em ciências sociais: a pesquisa qualitativa em educação. São Paulo: Atlas. 
Vygotsky, L. S. (1993). Pensamiento y Lenguaje. Conferencias sobre Psicología. In S. Vygotsky. Obras Escogidas II. (pp. 91-118). Madrid: Visor.

Zanatta Da Ros, S. (2002). Pedagogia e mediação em Reuven Feuerstein: o processo da mudança em adultos com história de deficiência. São Paulo: Plexus. 